\title{
BMJ Open Precision-Exercise-Prescription in patients with lung cancer undergoing surgery: rationale and design of the PEP study trial
}

Cornelia M Ulrich, ${ }^{1,2}$ Caroline Himbert, ${ }^{1,2}$ Kenneth Boucher, ${ }^{1,3}$ David W Wetter, ${ }^{1,2}$ Rachel Hess, ${ }^{2,4}$ Jaewhan Kim, ${ }^{1,5}$ Kelly Lundberg, ${ }^{6}$ Jennifer A Ligibel, ${ }^{7}$ Christopher A Barnes, ${ }^{8}$ Bailee Rushton, ${ }^{1}$ Robin Marcus, ${ }^{8}$ Samuel R G Finlayson, ${ }^{9}$ Paul C LaStayo, ${ }^{8}$ Thomas K Varghese ${ }^{9,10}$

To cite: Ulrich CM, Himbert C, Boucher $\mathrm{K}$, et al. PrecisionExercise-Prescription in patients with lung cancer undergoing surgery: rationale and design of the PEP study trial. BMJ Open 2018;8:e024672. doi:10.1136/ bmjopen-2018-024672

- Prepublication history for this paper is available online To view these files, please visit the journal online (http://dx.doi org/10.1136/bmjopen-2018024672).

PCLS and TKV contributed equally.

Received 13 June 2018 Revised 5 September 2018 Accepted 26 September 2018

Check for updates

(c) Author(s) (or their employer(s)) 2018. Re-use permitted under CC BY-NC. No commercial re-use. See rights and permissions. Published by BMJ.

For numbered affiliations see end of article.

Correspondence to Dr Cornelia M Ulrich; neli.ulrich@hci.utah.edu

\section{ABSTRACT}

Introduction Lung cancer is a significant burden on societies worldwide, and the most common cause of death in patients with cancer overall. Exercise intervention studies in patients with lung cancer have consistently shown benefits with respect to physical and emotional functioning. However, to date, exercise training has not been consistently implemented into clinical practice given that interventions have been costly and not aligned with clinical care. Methods/design The Precision-Exercise-Prescription (PEP) study is a prospective randomised controlled trial comparing the effectiveness and feasibility of a personalised intervention exercise programme among patients with lung cancer undergoing surgery. Twohundred patients who are diagnosed with stage primary or secondary lung cancer and are eligible to undergo surgical treatment at Huntsman Cancer Institute comprise the target population. Patients are randomised to either the (1) outpatient precision-exercise intervention group or (2) delayed intervention group. The intervention approach uses Motivation and Problem Solving, a hybrid behavioural treatment based on motivational interviewing and practical problem solving. The dosage of the exercise intervention is personalised based on the individual's Activity Measure for Post-Acute-Care outpatient basic mobility score, and incorporates four exercise modes: mobility, callisthenics, aerobic and resistance. Exercise is implemented by physical therapists at study visits from presurgery until 6 months postsurgery. The primary endpoint is the level of physical function assessed by 6 min walk distance at 2 months postsurgery. Secondary outcomes include patientreported outcomes (eg, quality of life, fatigue and selfefficacy) and other clinical outcomes, including length of stay, complications, readmission, pulmonary function and treatment-related costs up to 6 months postsurgery. Ethics/dissemination The PEP study will test the clinical effectiveness and feasibility of a personalised exercise intervention in patients with lung cancer undergoing surgery. Outcomes of this clinical trial will be presented at national and international conferences and symposia and will be published in international, peer-reviewed journals. Ethics approval was obtained at the University of Utah (IRB 00104671).

Trial registration number NCT03306992.
Strengths and limitations of this study

- This is the first randomised controlled trial to examine a personalised exercise programme for both patients with primary and secondary lung cancer.

- The intervention is designed to be aligned with and easily translatable into the clinical workflow and spans the entire continuum of care from the presurgery to postsurgery period including lung cancer survivorship.

- The intervention is designed so that it can successfully be translated into different populations, including rural and frontier populations that encounter challenges due to the distance to healthcare providers.

- The results will yield important healthcare cost information using the value-driven outcomes tool.

- The cost of the behavioural intervention delivered by a physical therapist for weekly phone calls during the outpatients period may still be too high for future implementation in healthcare settings.

\section{INTRODUCTION}

Lung cancer-both primary and secondaryis a significant source of morbidity and mortality worldwide. ${ }^{12}$ Primary lung cancer is the leading cause of cancer death in both men and women, causing more deaths than the next three cancers (breast, prostate, colon) combined. ${ }^{2}$ Lung metastases (secondary lung cancer) are identified in 30\%-50\% of all patients with cancer. ${ }^{1}$ The cost of cancer care for patients with lung cancer is significant and expected to exceed $\$ 14.7$ billion by 2020 (out of a total expense of cancer care of $\$ 157.7$ billion). ${ }^{3}$

Surgical intervention in localised primary non-small cell lung cancer (NSCLC) improves survival outcomes. ${ }^{4}$ Additionally, resection of isolated secondary lung cancer has led to increased progression-free and overall survival 
in patients with certain cancers such as sarcoma and colon cancer. ${ }^{5-10}$ Although surgery can improve outcomes in patients with early and, at times, later stage malignancies, surgical procedures a lead to significant morbidity in patients with cancer. Surgical patients suffer decreased pulmonary and physical function, reduced quality of life (QOL), chronic pain and reduced activity levels following surgery. ${ }^{11}{ }^{12}$ These effects can be ameliorated by exercise. Studies have shown that exercise training positively affects QoL, physical capacity and fatigue in patients with cancer, irrespective of the tumour type ${ }^{13-15}$ Initial exercise studies among patients with lung cancer during the preoperative and postoperative settings demonstrate improvement in physical performance, cardiorespiratory fitness and hospital length of stay. ${ }^{16-21}$ The consistency of these findings is compelling. ${ }^{16-41}$

Despite promising findings for exercise, translation to the clinic has not been achieved in large part because the interventions tested to date are cumbersome, expensive and not easy to implement in a busy clinical practice. For translation to succeed, an exercise regimen needs to be identified that can be easily integrated into the clinical workflow, and achieved with limited, yet effective, scope of financial resources and personnel. Such a regimen would be most effective if it used clinic contact points both prior to surgery and postsurgery. The Precision-Exercise-Prescription (PEP) Study (National Cancer Institute R01 CA211705) is a randomised phase III clinical trial $(n=200$ patients) that will investigate the effect of a personalised exercise programme on physical function, as measured by the 6 min walk ( $6 \mathrm{MW})$ test, in patients with NSCLC (stage I, II, IIIa) and patients with secondary lung cancer who are undergoing surgical treatment at the Huntsman Cancer Institute (HCI). Secondary aims including evaluating the impact of the intervention on other measures of physical function (short physical performance battery, SPPB), patient-reported outcomes (PROs) (QoL, fatigue, pain, sleep and self-efficacy), clinical outcomes (length of stay, complications, readmission and pulmonary function) and treatment-related cost.

We hypothesise that patients with lung cancer undergoing surgical resection will improve their physical function by participating in a PEP that is tailored to their mobility level, motivation, and other behavioural and environment factors as they progress (or regress) through the multiple phases of the presurgery and postsurgery periods. The PEP study will test an intervention that we expect will help patients with lung cancer undergoing surgery to maintain, regain and improve their physical function during the continuum from surgery to lung cancer survivorship.

\section{METHODS}

\section{Study design}

Screening eligibility and baseline data collection

We will conduct a single-centre, prospective, two-armed, phase III randomised controlled trial at HCI in Salt Lake City, Utah. All participants are required to provide written

\section{Box 1 Study inclusion and exclusion criteria}

\section{Inclusion criteria}

- Patient diagnosed with primary lung cancer stage I, II or IIla, or secondary lung cancer undergoing surgery at Huntsman Cancer Institute $(\mathrm{HCl})$.

- Diagnosis of primary lung cancer stage I, II, or IIla, or secondary lung cancer.

- Disease amenable to surgical resection to be performed at the $\mathrm{HCl}$ in the opinion of the treating surgeon.

- Patients must be able to follow directions and complete questionnaires and exercise diaries in English.

- Patients must agree to be randomly assigned to either intervention or delayed intervention group.

\section{Exclusion criteria:}

Deemed ineligible for surgery by the enrolling physician.

- Abnormalities on screening physical examination judged by study physicians or physical therapist to contraindicate participation in exercise programme compliance.

- Alcohol or drug abuse as judged by study physicians.

- Significant mental or emotional problems that would interfere with study participation will be assessed by the NCCN Distress Thermometer. Any value higher than seven will trigger further intervention, but ultimately enrolment into the clinical trial will be determined by the enrolling physician.

informed consent. Patients with NSCLC stage I, II or IIIa, or secondary lung cancer over 18 years old, who undergo surgical lung resection at HCI are recruited. Detailed eligibility criteria are listed in box 1 . Eligibility criteria for this study primarily focus on whether a patient is eligible for surgery or not.

The primary outcome measure of physical function, the $6 \mathrm{MW}$ test, is obtained by the licensed study physical therapist or trained study staff. Additional measurements are also obtained, including height, weight, waist and hip circumferences, systolic and diastolic blood pressure, resting $1 \mathrm{~min}$ pulse and patient-reported mobility status (Activity Measure for Post-Acute-Care outpatient basic mobility (AM-PAC) score). Patients receive a baseline questionnaire to either (1) complete in clinic or (2) take home to complete and return either by mail or at their presurgery appointment 2 weeks later. After randomisation (see AM-PAC score for exercise tailoring section) and completion of all baseline testing, patients start their intervention or control activities.

\section{Study participant schedule}

Figure 1 shows the proposed participant flow through the trial. Potential participants are approached during their first clinical visit prior to surgery (about 2-4 weeks presurgery). Consenting participants undergo required baseline assessments, which are presented for each study time point in table 1. Both groups are seen at the following study time points: presurgery (1 day before surgery), discharge (first visit after discharge from the hospital, 1-week postdischarge), 2 and 6 months postsurgery. 
CLINIC VISIT (2 weeks before surgery) Screening for eligibility by study staff $(n=272)$
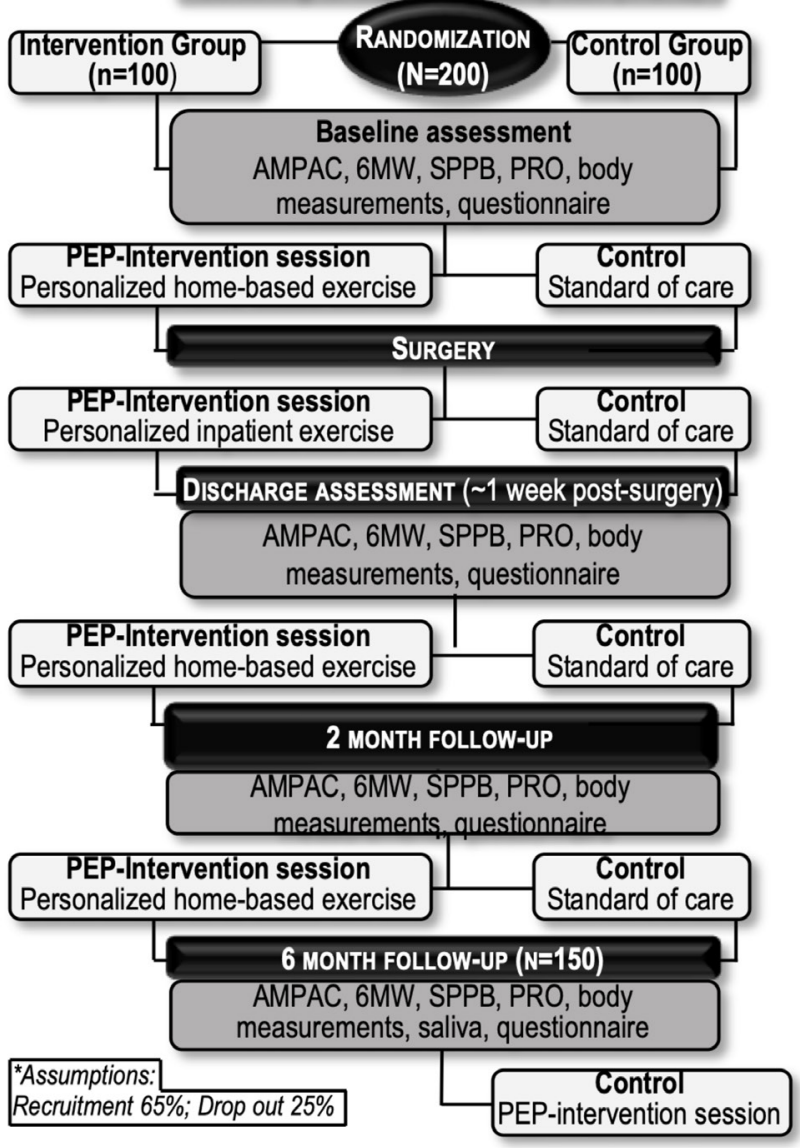

Figure 1 Participant flow chart for the PEP study. AM-PAC, Activity Measure for Post-Acute-Care; 6MW, 6 min walk; PEP, Precision-Exercise-Prescription; PRO, patient-reported outcomes; SPPB, short physical performance battery.

\section{AM-PAC score for exercise tailoring}

The AM-PAC basic mobility assessment (table 2) is completed on each day that the study participant is seen by a physical therapist. The AM-PAC Outpatient Basic Mobility Short Form (18 questions) takes about 2 min to complete and is used to precisely guide the exercise

Table 1 Activity Measure for Post-Acute-Care Stages according to Arbane. ${ }^{20}$

\section{Stage (score) function}

1 (0-34) Limited in bed, basic, transfers.

2 (35-52) Limited mobility inside of a building, unable to do bending/reaching activities.

3 (53-66) Little difficulty in moving inside a building but limited in going outdoors.

4 (67-84) Walks independently inside and outside, some difficulty in doing moderate or strenuous activities.

5 (85-100) Moves inside or outside independently and participants in strenuous sports. prescription for each patient in a personalised manner. The AM-PAC has high test-retest and subject-proxy reliability in outpatient settings $(0.97$ and 0.86 , respectively), and with inpatients the AM-PAC has a high intraclass correlation coefficient (0.85) when administered by clinicians. ${ }^{42-45}$ Scores on the AM-PAC correlate with well-established physical function subscales, for example, Functional Independence Measure $(\mathrm{r}=0.65)$. A standardised response mean of 1.06 and a minimal detectable change with $90 \%$ confidence of 4.72 has been delineated with AM-PAC. ${ }^{44}$

\section{Randomisation}

Consenting participants are stratified by their AM-PAC mobility stage (low mobility: stages 1, 2 and 3 vs high mobility: stages 4 and 5), and cancer type (primary vs secondary). Participants are randomised using a uniform 1:1 allocation ratio with random block sizes of eight individuals to either (1) Intervention group: PEP intervention or (2) Delayed intervention group: standard of care for 6 months with PEP intervention session after study completion. The allocation sequence is produced via computer-generated random numbers and concealed from clinical trials office (CTO) staff.

\section{STUDY ARMS \\ Intervention group}

The PEP intervention is personalised, implemented and modified based on the patients AM-PAC mobility stage, by a licensed physical therapist in face-to-face meetings $(\sim 30-40 \mathrm{~min})$ at: the presurgery visit with the surgeon; the discharge visit (about 1-week postdischarge from the hospital) and the 2-month postsurgery follow-up appointment with the surgeon. The intervention uses existing resources in the clinical setting and as such, is pragmatic and more generalisable than other exercise programmes. An exercise education manual is used by the physical therapist to educate the patients on all aspects of starting and maintaining the exercise intervention. The Intervention group is given access to exercise tools (eg, light weights and external resistance bands) as needed, tracking exercise diary/calendar and activity tracker for the home-based exercise programme (see below) at no cost. The study physical therapist goes over (verbally and in writing) the individual exercise modes and dosages to be performed at home. The exercise mode and dosage is standardised with respect to the patient's AM-PAC mobility stage (figure 2). The exercise mode and dosage may be further modified by the study physical therapist in response to physical impairments such as fatigue, muscle weakness, pain and shortness of breath. Modification of the intervention may also take place in order to encourage exercise adherence and to address psychosocial barriers. Resistance exercises, using body weight or exercise band resistance, are prescribed for the upper and lower body though more exercises are focused on the lower extremities than the upper extremities. For all exercises, including 
Table 2 PEP study schedule of enrolment, interventions and assessments

\begin{tabular}{|c|c|c|c|c|c|}
\hline \multirow[b]{3}{*}{ Time point } & \multicolumn{5}{|c|}{ Study period } \\
\hline & \multirow{2}{*}{$\begin{array}{l}\text { Enrolment } \\
\text { Baseline* }^{*}\end{array}$} & \multirow{2}{*}{$\begin{array}{l}\text { Surgery } \\
0\end{array}$} & \multicolumn{2}{|c|}{ Postallocation } & \multirow{2}{*}{$\begin{array}{l}\text { Close-out } \\
6 \text { months }\end{array}$} \\
\hline & & & Discharge & 2 months $¥$ & \\
\hline \multicolumn{6}{|l|}{ Enrolment } \\
\hline Eligibility screen & $\mathrm{x}$ & & & & \\
\hline Informed consent & $x$ & & & & \\
\hline Allocation & $x$ & & & & \\
\hline \multicolumn{6}{|l|}{ Interventions } \\
\hline Group 1 & $\longleftarrow$ & & & & $\longrightarrow$ \\
\hline Group 2 & & & & & X (Delayed intervention) \\
\hline \multicolumn{6}{|l|}{ Assessments } \\
\hline AM-PAC mobility score & $x$ & & $\mathrm{x}$ & $x$ & $\mathrm{x}$ \\
\hline 6 min walk distance & $\mathrm{x}$ & & $\mathrm{x}$ & $\mathrm{x}$ & $\mathrm{x}$ \\
\hline Short physical performance battery & $x$ & & $\mathrm{x}$ & $x$ & $x$ \\
\hline Patient-reported outcomes & $x$ & & $\mathrm{x}$ & $x$ & $\mathrm{x}$ \\
\hline Exercise diary provided/reviewed & $\mathrm{x}$ & $x$ & $\mathrm{x}$ & $x$ & $\mathrm{x}$ \\
\hline Follow-up questionnaires & & & $\mathrm{x}$ & $\mathrm{x}$ & $x$ \\
\hline Length of stay postsurgery & & & $\mathrm{x}$ & & \\
\hline Cost data & & & $x$ & $\mathrm{X}$ & $x$ \\
\hline Smoking assessment (saliva) & & & & & $x$ \\
\hline
\end{tabular}

*Baseline: first clinic visit with surgeon.

†Discharge visit: about 1 week after discharge from the hospital.

$\ddagger 2$ months visit: Two months postsurgery.

$\S 6$ months visit: Six months postsurgery.

AM-PAC, Activity Measure for Post-Acute-Care; PEP, Precision-Exercise-Prescription.

callisthenics and aerobic modes, bouts are defined by duration ranging from 5 to $30 \mathrm{~min}$, and intensity ranging from moderate to high intensity. Exercise intensity is determined by perceived exertion, with moderate-high intensity defined as activity that allows the participant to talk but not sing while exercising. For example, a patient in AM-PAC mobility stage 3 will perform aerobic exercise similar in intensity to walking on level surfaces for $10 \mathrm{~min}$ per day at a 'somewhat hard' perceived exertion, with the ability to talk but not sing during walking. Additionally,
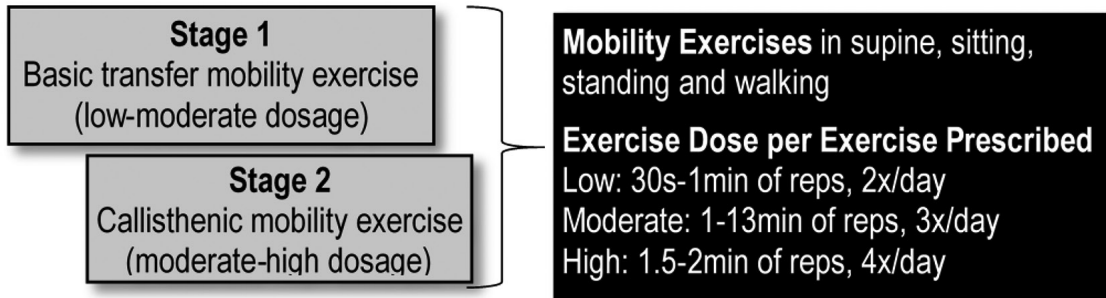

Aerobic (AE) and Resistance Exercises

(RE) during level walking, bending, inclines,

steps, squats, stairs, weights

Exercise Dose per Day

Low: "somewhat hard" + talk test

$\mathrm{AE}=10 \mathrm{~min} ; \mathrm{RE}=5 \mathrm{~min}$

Moderate: "somewhat hard" + talk test

$\mathrm{AE}=20 \mathrm{~min} ; \mathrm{RE}=10 \mathrm{~min}$

High: "hard" + talk test

$A E=30 \mathrm{~min} ; \mathrm{RE}=15 \mathrm{~min}$

\section{Stage 3}

Aerobic \& resistance exercise (low-moderate dosaqe)

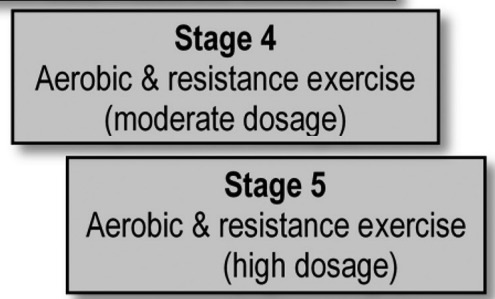

Figure 2 AM-PAC stage: exercise mode and dose. AM-PAC, Activity Measure for Post-Acute-Care. 
this patient will also perform a resistance exercise, such as standing squats, at the same perceived exertion for short bouts that add up to $5 \mathrm{~min}$ per day. These aerobic and resistance exercises will increase to $20 \mathrm{~min}$ and $10 \mathrm{~min}$ per day, respectively, as the participant progresses to AM-PAC mobility stage 4 .

Participants are encouraged to record the duration of each bout of exercise in their diaries, in accordance with the use of duration and intensity in the dosing of exercises, rather than counting sets and repetitions. With every exercise prescription or adjustment, participants are advised to maintain the level of exercise intensity appropriate to their AM-PAC stage. This is reinforced in interactions with PEP staff during weekly phone calls. Well-being, perceived exertion, pain, fatigue and other participant's responses to exercise are recorded in logs of weekly Motivational and Problem Solving (MAPS) phone calls. Any issues with exercise that require PT attention are referred to the study PT for intervention face to face in clinic or by phone at home. We may not achieve full completion rates given the severity of the disease of the study participants and disease-related comorbidities.

The outpatient exercises are performed at home, the HCI Wellness Center or a recreational centre. The exercise modes include basic mobility exercises, callisthenics, aerobic and resistance exercises, and are performed in various postures (supine, sitting, standing and walking) with variable challenges (eg, level walking, bending, incline walking, stair walking and squatting). Instructional exercise sheets demonstrating exercise modes and doses are handed out after each exercise intervention adjustment.

Telephone calls between the participant and the study staff (including the physical therapists and clinical research coordinator,) take place weekly to answer questions and optimise patient engagement. Ongoing monitoring of attitudes and barriers to exercise occurs, and strategies for encouraging uptake of the exercise intervention are individually tailored. A consumer wearable device (eg, Fitbit Flex II Wireless Activity Tracker) is used as a fundamental component to support behavioural change. This pragmatic motivational and self-monitoring tool is used to improve participant exercise efficacy and home exercise programme adherence. ${ }^{46}$

Specific components of the PEP intervention include: individualised tailoring of the exercise prescription; individualised tailoring of the counselling based on motivation and self-efficacy to engage in exercise including the use of simple motivational interviewing (MI) ${ }^{47}$ techniques (eg, reflective listening, avoiding argumentation, developing discrepancy); identifying barriers to exercising and problem-solving solutions; use of goal setting and self-monitoring (including via the activity tracker) and implementing specific strategies for improving self-efficacy (eg, building a series of small achievable goals; practising specific exercises during the face-to-face visits to increase mastery (figure 2).
MAPS is the hallmark behavioural intervention used in parallel with the exercise intervention. MAPS is a holistic, dynamic approach to facilitating behavioural change that uses a combined motivational enhancement and problem-solving approach based on MI and social cognitive theory. ${ }^{48}$ The behavioural intervention uses an overarching conceptual basis of the intervention is the social cognitive mode ${ }^{49-51}$ which posits that high levels of both motivation and self-efficacy are necessary for behavioural change. Thus, a key element for lasting behavioural change is a motivational shift that instigates a decision and commitment to change. In the absence of such a shift, skill training is viewed as premature. ${ }^{49} 52$ As such, the PEP intervention focuses on both enhancing the motivation to achieve and maintain change, as well as developing the self-efficacy and skills necessary to do so. MAPS or its precursors have been demonstrated to be effective in four randomised controlled trials with respect to: (1) increasing treatment utilisation, ${ }^{53}$ (2) enhancing behavioural change success rates ${ }^{54}$ (3) reducing relapse ${ }^{55}$ and (4) addressing multiple risk behavioural change. ${ }^{56}$ Interactions between patients and interventionists are coded and evaluated with respect to the quality of the interaction using a modified version of the Motivational Interviewing (MI) Treatment Integrity, including the ability to shift between MI strategies and more cognitive-behavioural or practical problem-solving skills. It is hypothesised that participants who received the MAPS intervention will have improved psychosocial and emotional outcomes, measured by study questionnaires, improved exercise adherence, as indicated by exercise diaries and 7-day physical activity recall interviews, and, most importantly, improved physical function as measured by $6 \mathrm{MW}$ and other performance-based outcomes.

In sum, the PEP intervention is a directive but patient-centred approach designed to enhance motivation for change, and increase self-efficacy in a non-confrontational manner. Several meta-analyses/systematic reviews have supported the efficacy of both social cognitive and MI-based interventions for behavioural change in general and with respect to patients with cancer specifically. ${ }^{57-61}$ As such, we believe the PEP intervention is an innovative combination of motivational enhancement and social cognitive intervention techniques.

\section{Delayed intervention group (control group)}

The delayed intervention group will receive standard therapy for their lung cancer. Although all patients, independent of group assignment are encouraged by clinical staff to increase walking both in the presurgery and postsurgery period (as part of HCI's usual clinical care), there is no formalised pre or postsurgery exercise programme. All patients will have equal access to the HCI Wellness Centre, as well as equal opportunity for referral to non-study physical therapists and other exercise professionals.

Patients will undergo assessments timed to coincide with regularly scheduled cancer care: the first postdischarge 
clinic visit is scheduled at 1 week after discharge from the hospital, with the second clinic visit at 2 months. On study completion (at the 6-month postsurgery follow-up visit), the delayed intervention group is offered a PEP-Intervention session with precision exercise counselling, and receives a free activity tracker.

\section{PRIMARY AND SECONDARY ENDPOINTS}

Endpoint assessments are presented in table 2. The primary endpoint is a physical function mobility performance assessment of the distance walked in 6 min (6 MW test) that will be assessed at the preoperative baseline and the three postsurgery time points. The $6 \mathrm{MW}$ test is the most pragmatic, non-laboratory test to measure mobility physical functioning in individuals with chronic lung disease (including lung cancer) ${ }^{62}$ In accordance with the American Thoracic Society recommendations, ${ }^{63}$ the $6 \mathrm{MW}$ test is a self-paced walking test with standardised instructions and encouragement that measures the distance $(\mathrm{m})$ the patient can walk indoors on a $25 \mathrm{~m}$ level, smooth-surfaced track over $6 \mathrm{~min}$. A number of studies have demonstrated the criterion predictive validity of the $6 \mathrm{MW}$ test in lung cancer with some demonstrating positive relationships between $6 \mathrm{MW}$ distance and postsurgery outcomes including QoL, survival, function and physical activity levels. ${ }^{64-67}$ The minimally clinically important difference of the $6 \mathrm{MW}$ distance in patients with lung cancer is $22-42 \mathrm{~m}^{67}$

Secondary endpoints include: the SPPB, which captures domains of strength, endurance and balance, and is highly predictive of disability ${ }^{68}$; PROs on physical, mental and social well-being measured by using generic-specific, as well as disease-specific instruments, such as data from the National Institutes of Health (NIH) Patient-Reported Outcomes Measurement Information System ${ }^{69}$; the Functional Assessment of Cancer Therapy-Lung ${ }^{70}$ and Functional Assessment of Chronic Illness Therapy-Fatigue to measure fatigue; the Pittsburgh Sleep Quality Index to assess the patients' sleep habits and quality; Behavioural Regulation in Exercise Questionnaire-3 $3^{72}$ and 7-day physical activity recall phone interview to monitor and compare physical activity levels across study arms, ${ }^{73}$ Diet History Questionnaire II to collect information on dietary lifestyle factors, ${ }^{74}$ self-efficacy by Sallis et al (the scale includes two subscales: (1) 'resting relapse/sticking to it' and (2) 'making time to exercise') ${ }^{75}$ Modified Differential Emotion Scale to capture emotional experiences ${ }^{76}$; Social Support for Exercise by Sallis et al, ${ }^{77}$ Subjective Social Status Ladders ${ }^{78}$ and financial strain ${ }^{79}$ to assess social status, loneliness by Cacioppo ${ }^{80}$; symptoms, such as pain (1-10 scale) and shortness of breath (1-10 scale), living condition, clinical endpoints, such as length of stay postsurgical resection, complications and healthcare costs, including inpatient hospitalisation and outpatient follow-up, using the University of Utah Value-Driven Outcomes cost database ${ }^{81}$ at 2-6months follow-up. We will test former smokers to assess smoking recidivism at the 6-month clinic visit by collecting and analysing saliva samples. Patients are required to quit smoking before they are eligible to undergo surgery, thus, no saliva is collected at baseline. Smoking history will be assessed prior to undergoing surgery using standardised questionnaires.

\section{STATISTICAL CONSIDERATIONS AND PRIMARY ENDPOINT ANALYSIS}

The trial analysis will follow the intention-to-treat principle, which implies all participants who will be randomised $(n=200)$ will be included in the analysis regardless of their adherence to the study. We hypothesise that the difference in the $6 \mathrm{MW}$ distance between the study arms (Intervention/Control) will be $>39.95 \mathrm{~m}$. This effect size stems from a meta-analysis, where 4 weeks of postsurgery exercise training provided a $39.95 \mathrm{~m}$ increase in the $6 \mathrm{MW}$ distance in patients with NSCLC. ${ }^{74}$ Consistent with Arbane,${ }^{20}$ we assume $\mathrm{SD}=100 \mathrm{~m}$ and correlation $=0.5$ between repeated $6 \mathrm{MW}$ test measurements on the same subject. Power to detect the treatment effect was estimated by simulation of an analysis of covariance model with $6 \mathrm{MW}$ test at 2 months postsurgery as outcome, treatment group as primary predictor and pretreatment $6 \mathrm{MW}$ test as covariate. For our primary endpoint, with at least 150 evaluable subjects (accounting for a 25\% drop-out rate) the estimated power is greater than or equal to $80 \%$ at two-sided type I error equal 0.05 .

Mixed-effects models with random intercept will be used for analysis of repeated measurements. A sensitivity analysis will be performed with additional adjustment variables (gender, age, baseline smoking status, primary or secondary lung cancer, neoadjuvant treatment, tumour stage, baseline level of outcome, pain and sleep). Missing data will be handled using multiple imputation via chained equations, as implemented by the $\mathrm{R}$ package Multivariate Imputation by Chained Equations (MICE) ${ }^{75}$

As of 31 October 2018, $\mathrm{n}=56$ patients have been recruited into the PEP study, with recruitment anticipated to continue through July 2020. To date, only four patients have withdrawn.

\section{PATIENT AND PUBLIC INVOLVEMENT}

A pilot study of 40 patients with lung cancer had been performed in the development of this trial. Every eligible patient was approached, and all patients approached $(100 \%)$ agreed to participate in the intervention. The observed $6 \mathrm{MW}$ distance varied from 209 to $679 \mathrm{~m}$ with a mean distance of $467+119 \mathrm{~m}$. Normal $6 \mathrm{MW}$ distance for healthy $60-69$ years old is $572 \mathrm{~m}$ for men and $538 \mathrm{~m}$ for women. The intervention included individually prescribed exercise modes (mobility, flexibility, calisthenic, aerobic and resistance) and dosages (low, moderate, high) tailored to the patient's AM-PAC mobility stage. To our knowledge, the AM-PAC mobility staging used to personalise exercise interventions was unique and facilitated the successful implementation 
of the intervention into clinical workflow using existing space in the clinic of Thoracic Surgery. Comparable control patients (for whom 6 MW distances at comparable pretime points and post-time points were available) PEP patients maintained their physical function and experienced a lesser reduction in 6 MW distance (median 6.8\% decline in PEP and $18.7 \%$ in controls. We have subsequently optimised our design and materials through the conduct of this pilot study. Our preliminary data reinforces that our pragmatic mobility screen (ie, AM-PAC score/staging) is the key determinant of physical function (independent of age, sex, cancer stage, etc) and that exercise modes and dosages can be successfully aligned to the AM-PAC score.

As part of the pilot study, we performed formal quality control interviews with patients to inform and refine the trial interventions and processes. The data from the pilot trial as well as the close work with the CTO at HCI have been used to ensure that the study protocol engages participants in a respectful, ethical and impactful way, while performing the PEP study intervention. The CTO and other HCI resources further provide assistance with the ethical standards of the trial, as well as the translation and dissemination of the research findings to community members, patients and cancer support groups. In addition, the study is conducted by an interdisciplinary team with long-standing expertise in exercise, behavioural interventions and surgery. Involved clinicians and researchers work with the target population on a daily bases and used theirexperience to inform the development of the research question, outcome measures and performance of the intervention.

\section{DISCUSSION}

The primary results from the PEP study will test the clinical effectiveness and feasibility of a personalised exercise intervention in patients with lung cancer undergoing surgery. This trial fills the gap in knowledge precisely, by testing an exercise intervention that can be readily integrated into the clinic and by obtaining data on functional efficacy and PROs.

The feasibility of the PEP study was tested in a successful pilot study and builds on studies that have been previously performed by the interdisciplinary investigator team, ${ }^{82-99}$ grated into the clinic and by obtaining data on functional efficacy and PROs. To our knowledge, the AM-PAC mobility score has not been used to personalise exercise and this is a well-validated and highly standardised instrument. The behavioural intervention approach builds on prior work using MAPS, ${ }^{91}$ a holistic and dynamic approach to assisting individuals to make positive behavioural changes.

In a recent opinion piece, Alfano et al argued that 'it is time to revitalise the link between cancer survivorship and rehabilitation and investigate a new model of comprehensive cancer rehabilitation involving a multidisciplinary team of providers. ${ }^{, 100}$ PEP will be responsive to this call for action-it will integrate a team of surgeons and physical therapists. The study will begin at the initial presurgery clinic visit and continue during the inpatient and outpatient postsurgery periods, thus helping patients with lung cancer undergoing surgery to maintain, regain and improve their physical function during the continuum from surgery to lung cancer survivorship.

\section{Author affiliations}

${ }^{1}$ Huntsman Cancer Institute, Salt Lake City, Utah, USA

2Department of Population Health Sciences, University of Utah, Salt Lake City, Utah, USA

${ }^{3}$ Division of Epidemiology, University of Utah, Salt Lake City, Utah, USA

${ }^{4}$ Division of General Internal Medicine, University of Utah, Salt Lake City, Utah, USA

${ }^{5}$ Department of Health and Kinesiology, University of Utah, Salt Lake City, Utah, USA

${ }^{6}$ Department of Psychiatry, University of Utah, Salt Lake City, Utah, USA

${ }^{7}$ Dana-Farber Cancer Institute, Harvard Medical School, Boston, Massachusetts, USA

${ }^{8}$ Department of Physical Therapy and Athletic Training, University of Utah, Salt Lake City, Utah, USA

${ }^{9}$ Department of Surgery, University of Utah, Salt Lake City, Utah, USA

${ }^{10}$ Division of Cardiothoracic Surgery, University of Utah, Salt Lake City, Utah, USA

Contributors All authors contributed to the design and development of the PEP Study protocol. Specifically, CMU, PCL, and TKV are the principal investigators of the trial. $\mathrm{CH}$ assisted with the design, implementation of a pilot study and implementation of the PEP Study. CH drafted the manuscript and the study protocol. $\mathrm{KB}$ provided statistical input, guidance and all calculations used in the design of the clinical trial. RH oversees the assessments of patient-reported outcomes as part of the PROMIS score. DWW and KL designed and conduct the behavioural support elements of the study intervention. JK is responsible for cost-effectiveness analyses and respective protocols. JAL, RM and SRGF provided significant input with respect to the design and performance of the trial. $C A B$ is the study physical therapist and assisted in the design of the personalised exercise intervention. $\mathrm{BR}$ assisted with the optimisation and implementation of the study protocol. $\mathrm{CMU}, \mathrm{CH}, \mathrm{KB}, \mathrm{DWW}, \mathrm{RH}$, $\mathrm{JK}, \mathrm{KL}, \mathrm{JAL}, \mathrm{CAB}, \mathrm{BR}, \mathrm{RM}$, SRGF, PCL and TKV contributed to writing, editing, review and approval of the study protocol, meeting the International Committee of Medical Journal Editors (ICMJE) recommendations for authorship. All authors reviewed and agreed the final manuscript.

Funding The PEP study is funded by the National Institutes of Health (NIH)/ National Cancer Institute (NCI) R01 CA211705 and Huntsman Cancer Foundation. Some authors were supported by grants from the NIH/NCI (R01 CA189184, R01 CA207371, U01 CA206110) and P30CA042014.

Competing interests None declared.

Patient consent Not required.

Ethics approval The PEP study has been approved by the Institutional Review Board of the University of Utah (IRB 00104671).

Provenance and peer review Not commissioned; externally peer reviewed.

Open access This is an open access article distributed in accordance with the Creative Commons Attribution Non Commercial (CC BY-NC 4.0) license, which permits others to distribute, remix, adapt, build upon this work non-commercially, and license their derivative works on different terms, provided the original work is properly cited, appropriate credit is given, any changes made indicated, and the use is non-commercial. See: http://creativecommons.org/licenses/by-nc/4.0/.

\section{REFERENCES}

1. Schwartz D, 2014. Secondary Lung TumorsDecember 08. http:// emedicine.medscape.com/article/426820-overview (Accessed 28 Oct 2016).

2. Siegel RL, Miller KD, Jemal A. Cancer statistics, 2016. CA Cancer J Clin 2016;66:7-30.

3. Mariotto AB, Yabroff KR, Shao Y, et al. Projections of the cost of cancer care in the United States: 2010-2020. J Natl Cancer Inst 2011;103:117-28.

4. Network NCC, 2016. NCCN guidelines-non-small cell lung cancer. Secondary NCCN guidelines-non-small cell lung cancer http://www. nccn.org/professionals/physician_gls/f_guidelines.asp 
5. Pastorino U, Buyse M, Friedel G, et al. Long-term results of lung metastasectomy: prognostic analyses based on 5206 cases. J Thorac Cardiovasc Surg 1997;113:37-49.

6. Hornbech K, Ravn J, Steinbrüchel DA. Outcome after pulmonary metastasectomy: analysis of 5 years consecutive surgical resections 2002-2006. J Thorac Oncol 2011;6:1733-40.

7. Younes RN, Fares AL, Gross JL. Pulmonary metastasectomy: a multivariate analysis of 440 patients undergoing complete resection. Interact Cardiovasc Thorac Surg 2012;14:156-61.

8. Larsen KR, Svendsen UG, Milman N, et al. Cardiopulmonary function at rest and during exercise after resection for bronchial carcinoma. Ann Thorac Surg 1997;64:960-4.

9. Casiraghi M, De Pas T, Maisonneuve P, et al. A 10-year singlecenter experience on 708 lung metastasectomies: the evidence of the "international registry of lung metastases". J Thorac Oncol 2011;6:1373-8.

10. Baser S, Shannon VR, Eapen GA, et al. Pulmonary dysfunction as a major cause of inoperability among patients with non-small-cell lung cancer. Clin Lung Cancer 2006;7:344-9.

11. Pompili C, Brunelli $A$, Xiumé F, et al. Predictors of postoperative decline in quality of life after major lung resections. Eur $J$ Cardiothorac Surg 2011;39:732-7.

12. Wildgaard K, Ravn J, Nikolajsen L, et al. Consequences of persistent pain after lung cancer surgery: a nationwide questionnaire study. Acta Anaesthesiol Scand 2011;55:60-8.

13. Kuehr L, Wiskemann J, Abel U, et al. Exercise in patients with nonsmall cell lung cancer. Med Sci Sports Exerc 2014;46:656-63.

14. Lakoski SG, Eves ND, Douglas PS, et al. Exercise rehabilitation in patients with cancer. Nat Rev Clin Oncol 2012;9:288-96.

15. Mock V, Pickett M, Ropka ME, et al. Fatigue and quality of life outcomes of exercise during cancer treatment. Cancer Pract 2001;9:119-27.

16. Hoffman AJ, Brintnall RA, Brown JK, et al. Too sick not to exercise: using a 6-week, home-based exercise intervention for cancerrelated fatigue self-management for postsurgical non-small cell lung cancer patients. Cancer Nurs 2013;36:175-88.

17. Jones LW, Eves ND, Peterson BL, et al. Safety and feasibility of aerobic training on cardiopulmonary function and quality of life in postsurgical nonsmall cell lung cancer patients: a pilot study. Cancer 2008;113:3430-9.

18. Jones LW, Eves ND, Peddle CJ, et al. Effects of presurgical exercise training on systemic inflammatory markers among patients with malignant lung lesions. Appl Physiol Nutr Metab 2009;34:197-202.

19. Peddle CJ, Jones LW, Eves ND, et al. Effects of presurgical exercise training on quality of life in patients undergoing lung resection for suspected malignancy: a pilot study. Cancer Nurs 2009;32:158-65.

20. Arbane G, Tropman D, Jackson D, et al. Evaluation of an early exercise intervention after thoracotomy for non-small cell lung cancer (NSCLC), effects on quality of life, muscle strength and exercise tolerance: randomised controlled trial. Lung Cancer 2011;71:229-34.

21. Sebio Garcia R, Yáñez Brage MI, Giménez Moolhuyzen E, et al. Functional and postoperative outcomes after preoperative exercise training in patients with lung cancer: a systematic review and meta-analysis. Interact Cardiovasc Thorac Surg 2016;23:486-97.

22. Benzo R, Wigle D, Novotny P, et al. Preoperative pulmonary rehabilitation before lung cancer resection: results from two randomized studies. Lung Cancer 2011;74:441-5.

23. Bobbio A, Chetta A, Ampollini L, et al. Preoperative pulmonary rehabilitation in patients undergoing lung resection for non-small cell lung cancer. Eur J Cardiothorac Surg 2008;33:95-8.

24. Cesario A, Ferri L, Galetta D, et al. Pre-operative pulmonary rehabilitation and surgery for lung cancer. Lung Cancer 2007:57:118-9.

25. Cesario A, Ferri L, Galetta D, et al. Post-operative respiratory rehabilitation after lung resection for non-small cell lung cancer. Lung Cancer 2007;57:175-80

26. Coats V, Maltais F, Simard S, et al. Feasibility and effectiveness of a home-based exercise training program before lung resection surgery. Can Respir J 2013;20:e10-6.

27. Divisi D, Di Francesco C, Di Leonardo G, et al. Preoperative pulmonary rehabilitation in patients with lung cancer and chronic obstructive pulmonary disease. Eur J Cardiothorac Surg 2013:43:293-6.

28. Granger CL, Chao C, McDonald CF, et al. Safety and feasibility of an exercise intervention for patients following lung resection: a pilot randomized controlled trial. Integr Cancer Ther 2013;12:213-24.

29. Jones LW, Peddle CJ, Eves ND, et al. Effects of presurgical exercise training on cardiorespiratory fitness among patients undergoing thoracic surgery for malignant lung lesions. Cancer 2007;110:590-8.
30. Peddle-Mclntyre CJ, Bell G, Fenton D, et al. Feasibility and preliminary efficacy of progressive resistance exercise training in lung cancer survivors. Lung Cancer 2012;75:126-32.

31. Pehlivan E, Turna A, Gurses A, et al. The effects of preoperative short-term intense physical therapy in lung cancer patients: a randomized controlled trial. Ann Thorac Cardiovasc Surg 2011;17:461-8.

32. Riesenberg $\mathrm{H}$, Lübbe AS. In-patient rehabilitation of lung cancer patients-a prospective study. Support Care Cancer 2010;18:877-82.

33. Sekine $\mathrm{Y}$, Chiyo M, Iwata $\mathrm{T}$, et al. Perioperative rehabilitation and physiotherapy for lung cancer patients with chronic obstructive pulmonary disease. Jpn J Thorac Cardiovasc Surg 2005;53:237-43.

34. Spruit MA, Janssen PP, Willemsen SC, et al. Exercise capacity before and after an 8-week multidisciplinary inpatient rehabilitation program in lung cancer patients: a pilot study. Lung Cancer 2006;52:257-60.

35. Stigt JA, Uil SM, van Riesen SJ, et al. A randomized controlled trial of postthoracotomy pulmonary rehabilitation in patients with resectable lung cancer. J Thorac Oncol 2013;8:214-21.

36. Wall LM. Changes in hope and power in lung cancer patients who exercise. Nurs Sci Q 2000;13:234-42.

37. Gao K, Yu PM, Su JH, et al. Cardiopulmonary exercise testing screening and pre-operative pulmonary rehabilitation reduce postoperative complications and improve fast-track recovery after lung cancer surgery: a study for 342 cases. Thorac Cancer 2015;6:443-9.

38. Pouwels S, Fiddelaers J, Teijink JA, et al. Preoperative exercise therapy in lung surgery patients: a systematic review. Respir Med 2015;109:1495-504.

39. Chang NW, Lin KC, Lee SC, et al. Effects of an early postoperative walking exercise programme on health status in lung cancer patients recovering from lung lobectomy. J Clin Nurs 2014;23:3391-402

40. Edvardsen $\mathrm{E}$, Skjonsberg $\mathrm{OH}$, Holme I, et al. High-intensity training following lung cancer surgery: a randomised controlled trial. Thorax 2015;70:244-50.

41. Chen HM, Tsai CM, Wu YC, et al. Randomised controlled trial on the effectiveness of home-based walking exercise on anxiety, depression and cancer-related symptoms in patients with lung cancer. Br J Cancer 2015;112:438-45

42. Jette DU, Stilphen M, Ranganathan VK, et al. Interrater reliability of AM-PAC "6-Clicks" basic mobility and daily activity short forms. Phys Ther 2015;95:758-66.

43. Jette DU, Stilphen M, Ranganathan VK, et al. AM-PAC "6-Clicks" functional assessment scores predict acute care hospital discharge destination. Phys Ther 2014;94:1252-61.

44. Jette DU, Stilphen M, Ranganathan VK, et al. Validity of the AMPAC "6-Clicks" inpatient daily activity and basic mobility short forms. Phys Ther 2014;94:379-91.

45. Andres PL, Haley SM, Ni PS. Is patient-reported function reliable for monitoring postacute outcomes? Am J Phys Med Rehabil 2003;82:614-21.

46. Bourke L, Homer KE, Thaha MA, et al. Interventions for promoting habitual exercise in people living with and beyond cancer. Cochrane Database Syst Rev 2013;92:Cd010192.

47. Miller W, Rollnick S. Motivational interviewing helping people change. 3rd edn: New York. NY: Guilford Press, 2014.

48. Vidrine JI, Reitzel LR, Figueroa P, et al. Motivation and Problem Solving (MAPS): Motivationally-based skills training for treating substance abuse. Cognitive Behavioral Practice. 2011

49. Marlatt GA, Donovan DM. Relapse prevention: maintanance strategies in the treatment of addictive behaviors. New York, NY Guliford Press, 2005.

50. Bandura A. Health promotion by social cognitive means. Health Educ Behav 2004;31:143-64.

51. Marlatt GA, Gordon JR. Relapse prevention: maintenance strategies in the treatment of addictive behaviors. New York, NY: Guilford Press, 1985

52. Rollnick S, Miller WR. What is motivational interviewing? Behav Cogn Psychother 1995;23:325

53. McClure JB, Westbrook E, Curry SJ, et al. Proactive, motivationally enhanced smoking cessation counseling among women with elevated cervical cancer risk. Nicotine Tob Res 2005;7:881-9.

54. Wetter DW, Mazas C, Daza P, et al. Reaching and treating spanish-speaking smokers through the national cancer institute's cancer information service. A randomized controlled trial. Cancer 2007;109:406-13.

55. Reitzel LR, Vidrine JI, Businelle MS, et al. Preventing postpartum smoking relapse among diverse low-income women: a randomized clinical trial. Nicotine Tob Res 2010;12:326-35. 
56. Correa-Fernández V, Díaz-Toro EC, Reitzel LR, et al. Combined treatment for at-risk drinking and smoking cessation among puerto ricans: a randomized clinical trial. Addict Behav 2017;65:185-92.

57. Rubak S, Sandbaek A, Lauritzen T, et al. Motivational interviewing: a systematic review and meta-analysis. Br J Gen Pract 2005;55:305-12.

58. Burke BL, Arkowitz H, Menchola M. The efficacy of motivational interviewing: a meta-analysis of controlled clinical trials. J Consult Clin Psychol 2003;71:843-61.

59. Martins RK, McNeil DW. Review of Motivational Interviewing in promoting health behaviors. Clin Psychol Rev 2009;29:283-93.

60. Spencer JC, Wheeler SB. A systematic review of Motivational Interviewing interventions in cancer patients and survivors. Patient Educ Couns 2016;99:1099-105.

61. Stacey FG, James EL, Chapman K, et al. A systematic review and meta-analysis of social cognitive theory-based physical activity and/or nutrition behavior change interventions for cancer survivors. J Cancer Surviv 2015;9:305-38.

62. Granger CL, McDonald CF, Berney S, et al. Exercise intervention to improve exercise capacity and health related quality of life for patients with non-small cell lung cancer: a systematic review. Lung Cancer 2011;72:139-53.

63. Society AT. 98th International conference of the American thoracic society. Atlanta, Georgia: Society AT, 2002.

64. Jones LW, Hornsby WE, Goetzinger A, et al. Prognostic significance of functional capacity and exercise behavior in patients with metastatic non-small cell lung cancer. Lung Cancer 2012;76:248-52.

65. Saad IA, Botega NJ, Toro IF. Predictors of quality-of-life improvement following pulmonary resection due to lung cancer. Sao Paulo Med J 2007:125:46-9.

66. Kasymjanova G, Correa JA, Kreisman H, et al. Prognostic value of the six-minute walk in advanced non-small cell lung cancer. $J$ Thorac Oncol 2009;4:602-7.

67. Granger CL, Holland AE, Gordon IR, et al. Minimal important difference of the 6-minute walk distance in lung cancer. Chron Respir Dis 2015:12:146-54.

68. Guralnik JM, Simonsick EM, Ferrucci L, et al. A short physical performance battery assessing lower extremity function: association with self-reported disability and prediction of mortality and nursing home admission. J Gerontol 1994;49:M85-94.

69. PROMIS. PROMIS-Dynamic tools to measure health outcomes from the patient perspective. 2011.

70. Cella DF, Bonomi AE, Lloyd SR, et al. Reliability and validity of the Functional Assessment of Cancer Therapy-Lung (FACT-L) quality of life instrument. Lung Cancer 1995;12:199-220.

71. Markland D, Tobin V. A modification to the behavioural regulation in exercise questionnaire to include an assessment of amotivation. Journal of Sport and Exercise Psychology 2004;26:191-6.

72. Wilson PM, Blanchard CM, Nehl E, et al. Predicting physical activity and outcome expectations in cancer survivors: an application of self-determination theory. Psychooncology 2006;15:567-78.

73. Sallis JF, Buono MJ, Roby JJ, et al. Seven-day recall and other physical activity self-reports in children and adolescents. Med Sci Sports Exerc 1993;25:99-108.

74. Beasley JM, Davis A, Riley WT. Evaluation of a web-based, pictorial diet history questionnaire. Public Health Nutr 2009;12:651-9.

75. Sallis JF, Pinski RB, Grossman RM, et al. The development of selfefficacy scales for healthrelated diet and exercise behaviors. Health Educ Res 1988;3:283-92.

76. Fredrickson BL, Tugade MM, Waugh CE, et al. What good are positive emotions in crises? A prospective study of resilience and emotions following the terrorist attacks on the United States on September 11th, 2001. J Pers Soc Psychol 2003;84:365-76.

77. Sallis JF, Grossman RM, Pinski RB, et al. The development of scales to measure social support for diet and exercise behaviors. Prev Med 1987;16:825-36.

78. Adler NE, Epel ES, Castellazzo G, et al. Relationship of subjective and objective social status with psychological and physiological functioning: preliminary data in healthy white women. Health Psychol 2000;19:586-92.
79. de Souza JA, Yap BJ, Hlubocky FJ, et al. The development of a financial toxicity patient. -reported outcome in cancer: the COST measure. Cancer 2014;120:3245-53.

80. Hughes ME, Waite LJ, Hawkley LC, et al. A short scale for measuring loneliness in large surveys: results from two populationbased studies. Res Aging 2004;26:655-72.

81. Kawamoto K, Martin CJ, Williams K, et al. Value Driven Outcomes (VDO): a pragmatic, modular, and extensible software framework for understanding and improving health care costs and outcomes. $J$ Am Med Inform Assoc 2015;22:223-35.

82. Farjah F, Flum DR, Varghese TK, et al. Surgeon specialty and longterm survival after pulmonary resection for lung cancer. Ann Thorac Surg 2009;87:995-1006.

83. Farjah F, Backhus L, Cheng A, et al. Failure to rescue and pulmonary resection for lung cancer. $J$ Thorac Cardiovasc Surg 2015;149:1365-73.

84. Varghese TK. Comparative effectiveness issues in lung cancer. Cancer Treat Res 2015;164:101-19.

85. LaStayo PC, Marcus RL, Dibble LE, et al. Eccentric exercise versus usual-care with older cancer survivors: the impact on muscle and mobility-an exploratory pilot study. BMC Geriatr 2011;11:5.

86. Campo RA, Agarwal N, LaStayo PC, et al. Levels of fatigue and distress in senior prostate cancer survivors enrolled in a 12-week randomized controlled trial of Qigong. J Cancer Surviv 2014;8:60-9.

87. Jacobs JL, Marcus RL, Morrell G, et al. Resistance exercise with older fallers: its impact on intermuscular adipose tissue. Biomed Res Int 2014;2014:1-7.

88. Wetter DW, McClure JB, Cofta-Woerpel L, et al. A randomized clinical trial of a palmtop computer-delivered treatment for smoking relapse prevention among women. Psychol Addict Behav 2011;25:365-71.

89. Reitzel LR, McClure JB, Cofta-Woerpel L, et al. The efficacy of computer-delivered treatment for smoking cessation. Cancer epidemiology, biomarkers \& prevention. 2011;20:1555-7.

90. Vidrine Jl, Shete S, Cao Y, et al. Ask-Advise-Connect: a new approach to smoking treatment delivery in health care settings. JAMA Intern Med 2013;173:458-64.

91. Vidrine JI, Reitzel LR, Figueroa PY, et al. Motivation and problem solving (MAPS): motivationally based skills training for treating substance use. Cogn Behav Pract 2013;20:501-16.

92. Nickman NA, Haak SW, Kim J. Cost minimization analysis of different growth hormone pen devices based on time-and-motion simulations. BMC Nurs 2010;9:6.

93. Hanmer J, Feeny D, Fischhoff B, et al. The PROMIS of QALYs. Health Qual Life Outcomes 2015;13:122.

94. Akerley W, Boucher KM, Bentz JS, et al. A phase II study of erlotinib as initial treatment for patients with stage IIIB-IV non-small cell lung cancer. J Thorac Oncol 2009;4:214-9.

95. Wiskemann J, Kuehl R, Dreger P, et al. Efficacy of exercise training in SCT patients-who benefits most? Bone Marrow Transplant 2013.

96. Ungar N, Sieverding M, Ulrich CM, et al. What explains the intention to be physically active in cancer patients? Different determinants for active and insufficiently active patients. $J$ Psychosoc Oncol 2015;33:15-33.

97. Schmidt ME, Meynköhn A, Habermann N, et al. Resistance exercise and inflammation in breast cancer patients undergoing adjuvant radiation therapy: mediation analysis from a randomized, controlled intervention trial. Int J Radiat Oncol Biol Phys 2016;94:329-37.

98. Ligibel JA, Giobbie-Hurder A, Olenczuk D, et al. Impact of a mixed strength and endurance exercise intervention on levels of adiponectin, high molecular weight adiponectin and leptin in breast cancer survivors. Cancer Causes Control 2009:20:1523-8.

99. Ligibel JA, Partridge A, Giobbie-Hurder A, et al. Physical and psychological outcomes among women in a telephone-based exercise intervention during adjuvant therapy for early stage breast cancer. J Womens Health 2010;19:1553-9.

100. Alfano CM, Ganz PA, Rowland JH, et al. Cancer survivorship and cancer rehabilitation: revitalizing the link. J Clin Oncol 2012;30:904-6. 